\title{
Influences of Temperature of Vapour-Condenser and Pressure in the Vacuum Chamber on the Cooling Rate during Vacuum Cooling
}

\author{
Tingxiang Jin*, Gailian Li, and Chunxia $\mathrm{Hu}$ \\ School of Mechanical \& Electricity engineering, Zhengzhou University of Light Industry, \\ 5 Dong Feng Road, Zhengzhou 450002, Henan Province, P. R. China \\ Tel.: +86-371-63556785 \\ txjin@126.com
}

\begin{abstract}
The temperature of vapour-condenser below $0^{\circ} \mathrm{C}$ and the final pressure in the vacuum chamber below $0.61 \mathrm{kPa}$ during vacuum cooling were experimentally analysed in this paper. The temperature of vapour-condenser, $-2^{\circ} \mathrm{C}$, $-35^{\circ} \mathrm{C},-39^{\circ} \mathrm{C}$ and $-71^{\circ} \mathrm{C}$, and the final pressure in the vacuum chamber, $0.3 \mathrm{kPa}$, $0.4 \mathrm{kPa}, 0.5 \mathrm{kPa}$ and $0.61 \mathrm{kPa}$, were chosen. The experimental results showed that the cooling rate varies with the temperature of vapour-condenser and the final pressure in the vacuum chamber. Water vapour becomes the frost on the surface of vapour-condenser when the initial temperature of vapour-condenser is below $0^{\circ} \mathrm{C}$, which is helpful to trap water vapour for vapour-condenser. In addition, the formation mechanism of frost at the surface of vapour-condenser was analysed in this paper. The cooling time for vacuum cooling can be reduced when the final pressure in the vacuum chamber varied from $0.4 \mathrm{kPa}$ to $0.61 \mathrm{kPa}$. However, the surface temperature of cooked meat occurred freezing when the final pressure in the vacuum chamber was $0.3 \mathrm{kPa}$. Therefore, in order to reduce the cooling time and avoid freezing, the temperature of vapour-condenser should be set around $30^{\circ} \mathrm{C} \sim-40^{\circ} \mathrm{C}$ and the final pressure in the vacuum chamber can be defined at from $0.4 \mathrm{kPa}$ to $0.61 \mathrm{kPa}$.
\end{abstract}

Keywords: Temperature; Pressure; Vapour-condenser; Vacuum cooling.

\section{Introduction}

Vacuum cooling is a rapid evaporative cooling method. Vacuum cooling has been successfully used to cool vegetables and flowers since the 1950s [1]. In the recent years, for the safety of foods, a rapid cooling treatment after cooking process should be used to minimize the growth of surviving organisms. Compared with the conventional cooling methods including air-blast, slow-air and water-immersion cooling, vacuum cooing has many advantages. Therefore, many researches have highlighted the applications of vacuum cooling for the cooked meats [2-4]. In addition, heat and mass transfer characteristics during vacuum cooling have been investigated [5].

\footnotetext{
* Corresponding author.
} 
Predictive models can provide much valuable information for the cooling process of large cooked meat joints under broad experimental conditions within a short time. Wang and Sun have developed a mathematical model for describing the vacuum cooling process of the large cooked meat joints [6-9].

\section{Nomenclature}

$Q_{0}$ - cold load of vapour-condenser, $W$;

$R_{v}$ - gas constant for water vapour, $\mathrm{J} \cdot \mathrm{mol}^{-1} \cdot \mathrm{K}^{-1}$;

$h_{v s}$ - sublimation heat of ice, $J \cdot \mathrm{kg}^{-1}$;

$T$ - the Kelvin temperature, $K$;

$\dot{m}$ - mass flux, $\mathrm{kg} \cdot \mathrm{s}^{-1}$;

$v$ - specific volume, $\mathrm{m}^{3} \cdot \mathrm{kg}^{-1}$;

$P$ - pressure, $P a$;

$D$ - the diffusivity, $m^{2} \cdot s^{-1}$;

Greeks

$\rho$-density $\mathrm{kg} \cdot \mathrm{m}^{-3}$;

$\lambda$ - thermal conductivity, $J \cdot m^{-1} \cdot K^{-1} \cdot s^{-1}$;

Subscripts

$f r$ - frost layer ;

$v$ - vapour ;

ice- ice layer;

A vacuum cooler is a machine to maintain the defined vacuum pressure in a sealed chamber, where the boiling of the water in the cooked meats occurs to produce the cooling effect. Theoretically, only the speed of vacuum pump is high enough to produce the defined vacuum pressure in the vacuum chamber. However, at a low pressure, the volume ratio of steam and water is very large. For example, when the pressure is $1073 \mathrm{~Pa}$, the corresponding saturation temperature is $8^{\circ} \mathrm{C}$, the specific volume is $120.851 \mathrm{~m}^{3} / \mathrm{kg}$. If the entire vapour is evacuated only through the vacuum pump, the speed of vacuum pump should be very large, many vacuum pumps are required in the vacuum cooler, which is obviously unsuitable. In order to remove the large amount of water vapour and keep the cooling cycle within a reasonable length of time, the vapour-condenser is used to economically and practically handle the large volume of water vapour by condensing the vapour back to water and then draining it through the drain valve. The vacuum pump and the vapour-condenser in the vacuum cooling system are used to remove the water vapour evaporated from the cooked meats. Wang and Sun [10] analysed the effect of operating conditions of a vacuum cooler on the cooling performance for large cooked meat joints by a validated mathematical model, they concluded that the temperature of the vapour-condenser should 
be above $0^{\circ} \mathrm{C}$, because water freezes on the outside surface of the condenser when the temperature is below $0^{\circ} \mathrm{C}$. It is well known that the boiling point changes as a function of saturation pressure, for a boiling temperature of $0^{\circ} \mathrm{C}$, the saturation pressure will be $609 \mathrm{~Pa}$. Therefore, in order to avoid freezing, the final pressure in the vacuum chamber is usually above $609 \mathrm{~Pa}$.

On the base of previous literatures, in the current study, vacuum cooling of cooked meats were conducted to analyze the effects of the final pressure in the vacuum chamber below $609 \mathrm{~Pa}$ and the temperature of vapour-condenser below $0^{\circ} \mathrm{C}$ on the cooling rate of cooked meats.

\section{Materials and Methods}

\subsection{Samples Preparation}

The raw bone-out pork used in experiments was brought from a local supermarket. Then, the samples were cooked in water through the oven (Type of the oven is RFP130Y, China) until the samples were at a uniform temperature. Then, the cooked meat was put and cooled in the vacuum chamber.

\subsection{Experimental Setup}

A laboratory-scale vacuum cooler as shown in Fig. 1 was built by Shanghai Pudong Freezing Dryer Instruments Co. Ltd. (Shanghai, China). Vacuum cooler has four basic components: a vacuum chamber, a vacuum pump, a vapour-condenser and a refrigeration system. The volume of vacuum chamber was approximately $0.3 \mathrm{~m}^{3}$. The rotary vane vacuum pump (Type 2XZ-2) with the pumping speed of $7.2 \mathrm{~m}^{3} \mathrm{~h}^{-1}$ and rotary speed $1400 \mathrm{rev} \mathrm{min}^{-1}$ was used to evacuate the air in the vacuum chamber and the vapour evaporated from the products from atmospheric pressure to the defined vacuum pressure. The final vacuum pressure in the vacuum chamber is regulated by the bleeding valve. The vapour-condenser is an evaporator in the refrigeration system and a condenser capturing water vapour evaporated from the cooked meats during vacuum cooling. The cooling coil of vapour-condenser is set up in a stainless cylindrical steel, which is enclosed with $30 \mathrm{~mm}$ thickness polyurethane foam to prevent heat transfer. The stainless cylindrical steel with vapor-condenser is defined as cold trap.

\subsection{Data Collection}

A set of T-type copper-constantan thermocouples with an accuracy of $\pm 0.1{ }^{\circ} \mathrm{C}$ are used to record the temperature distribution of cooked meats and the temperature of the cold trap. The pressure sensor (model CPCA-130Z), a capacitance membrane gauge with an accuracy of $\pm 1 \mathrm{~Pa}$ was used to measure the vacuum pressure in the chamber. The data collection and control signals, such as pressure and temperature were conducted by I-7000, a family of network data acquisition and control modules. The control module was connected with software called "King of Combination" (Beijing Asia Control Automatic Software Co. Ltd.). In order to eliminate the error of the second conversion, the temperatures received by the computer were demarcated by a second scale standard mercury thermometer with a measurement range $0 \sim 100^{\circ} \mathrm{C}$. 


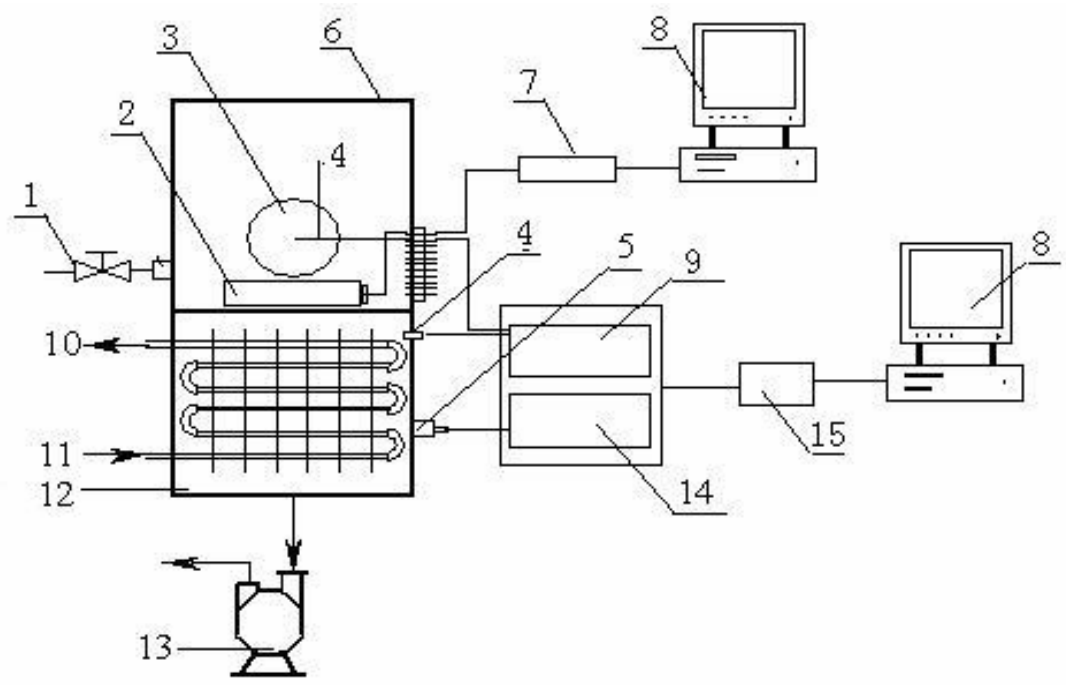

1-bleeding valve; 2-weight sensor; 3-sample; 4-thermal couple; 5-pressure sensor; 6-vacuum chamber; 7-electronic balance; 8-compute; 9-temperature controller; 10-coolant outlet; 11coolant inlet; 12-cold trap; 13-vacuum pump; 14-pressure controller; 15-I-7018P module

Fig. 1. Schematic diagram of the vacuum cooler system

\section{Results and Discussion}

\subsection{The Effect of Temperature of Vapour-Condenser on Cooling Rates during Vacuum Cooling}

The vapour-condenser, which is an auxiliary vacuum pump, is normally used to remove the large amount of water vapour generated by condensing the vapour back to water and draining the water out of the vacuum chamber. The effect of temperature of vapour-condenser on cooling rates is shown in Fig. 2. It can be seen from Fig. 2 that the cooling rate of cooked meat can increase with the reduction of temperature of vapour-condenser. During vacuum cooling, the temperature of vapour-condenser of below $0^{\circ} \mathrm{C}$ was used. However, if the temperature of vapour-condenser was too low, the cooling rate of cooked meat can decrease. If $0.15 \mathrm{~kg}$ of cooked meat was cooled, the average temperature of cooked meat can be reduced from $61.4^{\circ} \mathrm{C}$ to $4.7^{\circ} \mathrm{C}$ within $30 \mathrm{~min}$ at the vapour-condenser temperature of $-2^{\circ} \mathrm{C}$. In addition, when the temperature of vapour-condenser was further reduce from $-2{ }^{\circ} \mathrm{C}$ to $-39^{\circ} \mathrm{C}$, the total cooling time can be obviously reduced from $30 \mathrm{~min}$ to $20 \mathrm{~min}$. On the other hand, if the mass of cooked meat was $0.5 \mathrm{~kg}$, the temperature of vapour-condenser was reduced continuously to $-71{ }^{\circ} \mathrm{C}$, the average temperature of cooked meat decreased only from $74^{\circ} \mathrm{C}$ to $26.1^{\circ} \mathrm{C}$ within $42 \mathrm{~min}$. In the same mass of cooked meat, the average temperature of cooked meat can be reduced from $60.1^{\circ} \mathrm{C}$ to $5.7^{\circ} \mathrm{C}$ within $50 \mathrm{~min}$ at the vapour-condenser temperature of $-35^{\circ} \mathrm{C}$. During vacuum cooling, the mass of cooked 
meat has also an effect on the cooling rate, which is accorded with Wang and Sun's [10] experimental result. Wang and Sun [10] think that the temperature of vapourcondenser should be set at around $2.5^{\circ} \mathrm{C}$ above $0^{\circ} \mathrm{C}$ in order to avoid freezing of water on the outside surface of the cold trap. However, author thinks that the temperature of vapour-condenser should be set below $0^{\circ} \mathrm{C}$. Because when the temperature of vapour-condenser is below $0^{\circ} \mathrm{C}$, the water vapour become frost through solidify on the surface of the vapour-condenser, water vapour can be easily trapped in the vapourcondenser. It can be found that the different temperatures of vapour-condenser below $0^{\circ} \mathrm{C}$ have an effect on the cooling rate of cooked meat. However, if the temperature of vapour-condenser is too low, the cooling time can be increase adversely, which can be expressed by the formation of the frost on the surface of cold trap.

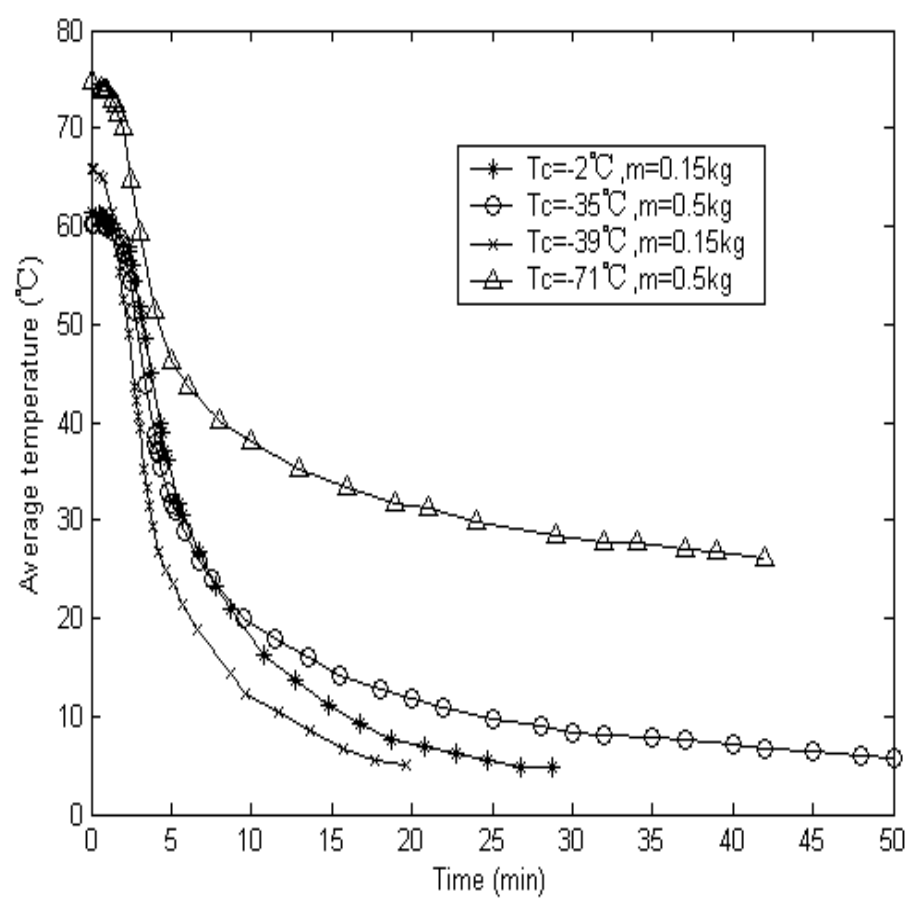

Fig. 2. Effect of temperature of vapour condenser on cooling rate during vacuum cooling

\subsection{The Formation Mechanism of the Frost on the Surface of Vapour-Condenser}

Fig. 3 shows the formation process of frost. The sensible heat is transferred from the water vapour in the vapour-condenser to the frost surface by the temperature difference driving force between the water vapour and the frost surface. Some of the transferred moisture deposits on the frost layer, causing the frost layer to grow. The remainder diffuses into the frost layer. The heat of sublimation caused by the phase change of the added frost layer is transferred through the frost layer. The latent heat 
and sensible heat transferred from the water vapour are then transferred through the frost layer by conduction. The water vapour diffusing into the frost layer changes phase within the frost layer. The frost density increases as a result of this process.

The frost layer is a porous medium composed of ice crystal and air. The ice crystal has different shapes during the formation of the frost layer. Ice crystal shapes are classified into main forms: plate-like forms and column-like forms. The microscopic structure of ice crystal is shown as in Fig.4.

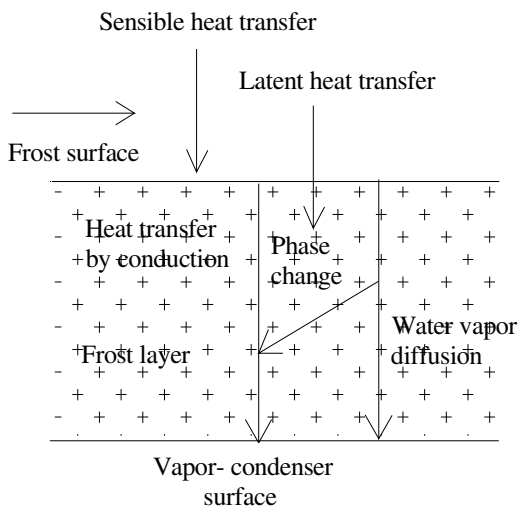

Fig. 3. The formation process of the frost
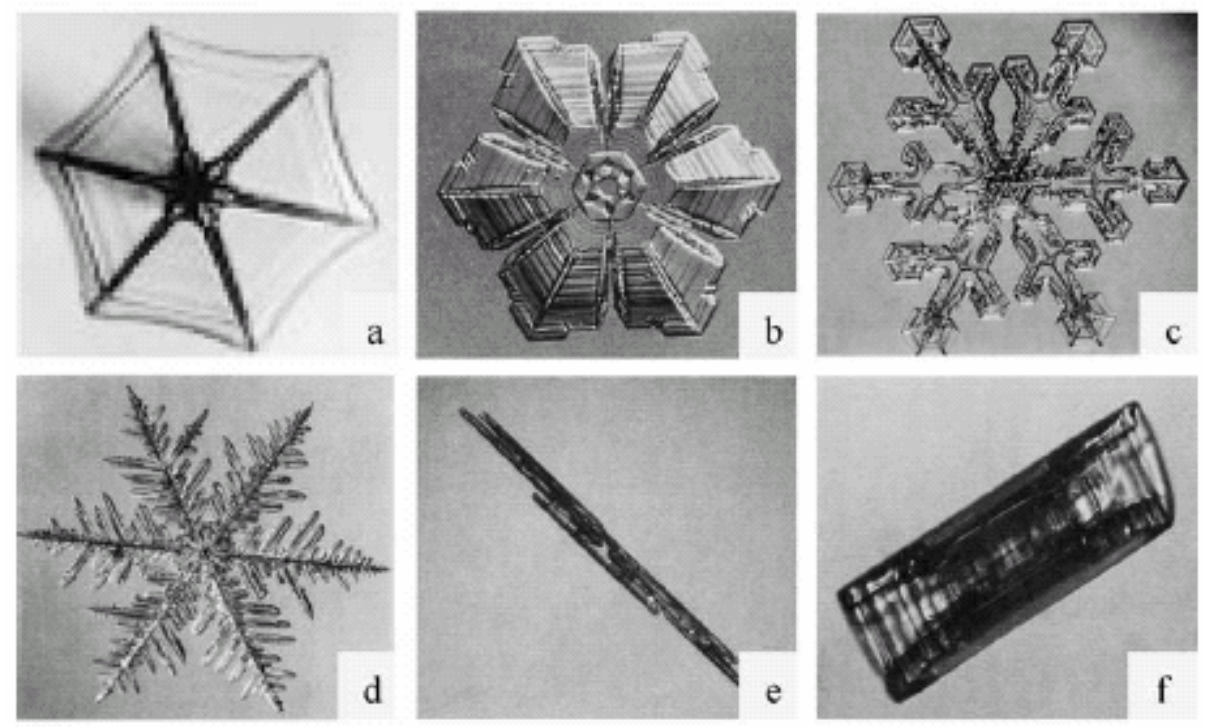

Fig. 4. Ice crystal shape (1) Plate-like forms: (a) plate, (b) simple sectored plate, (c) dendritic sectored plate, (d) fern-like stellar dendrite; (2) Column-like forms: (e) needle crystal, (f) hollow column, or sheath-like crystal [11] 
During the formation of the frost, the mass flux through water vapour diffusing into the frost layer can be calculated by the Clapeyron-Clausius equation. The expression is as follows [12]:

$$
\dot{m}_{f r}=\frac{Q_{0}}{h_{v s}+\frac{\lambda_{f r} R T_{f r}^{2}\left(v_{v}-v_{i c e}\right)\left[1+\left(\frac{\rho_{f_{r}}}{\rho_{i c e}}\right)^{0.5}\right]}{D_{v}\left[h_{v s}-P_{v}\left(v_{v}-v_{i c e}\right)\right]\left(1-\frac{\rho_{f_{r}}}{\rho_{i c e}}\right)}}
$$

Where $Q_{0}$ is the refrigeration load of vapour-condenser;

$h_{v s}$ is the sublimation heat of ice;

$R$ is the gas constant;

$T_{f r}$ is the surface temperature of the frost layer;

$v_{v}$ and $v_{\text {ice }}$ are respectively specific volume of water vapour and ice;

$\rho_{f_{r}}$ and $\rho_{i c e}$ are respectively density of frost layer and ice;

$P_{v}$ is the partial pressure of water vapour;

$D_{v}$ is the diffusivity of water vapour;

$\lambda_{f r}$ is the thermal conductivity of the frost layer, the expression is as follows [13]:

$$
\lambda_{f r}=0.02422+7.214 \times 10^{-4} \rho_{f r}+1.1797 \times 10^{-6} \rho_{f r}^{2}
$$

The temperature of vapour-condenser is below $0^{\circ} \mathrm{C}$, The water vapour evaporated from the cooked meats will become the frost at the surface of vapour-condenser. Fig. 5 shows that the comparison of the cold trap between before and after vacuum cooling of cooked meat. It can be obviously found that the frost occurs at the surface of cold trap after vacuum cooling of cooked meat.

The latent heat of sublimation is released in the cold trap, which can increase the temperature of vapour-condenser. The variation of temperature of vapour-condenser is shown in Fig. 6. It can be seen from Figs. 2 and 6 that when the initial temperatures of cold trap were at $-2^{\circ} \mathrm{C},-39^{\circ} \mathrm{C}$ and $-35^{\circ} \mathrm{C}$, respectively, the temperatures of cooked meat were reduced to about $5^{\circ} \mathrm{C}$, the temperature of vapour-condenser was reduced from $-2^{\circ} \mathrm{C},-39^{\circ} \mathrm{C}$ and $-35^{\circ} \mathrm{C}$ to $-70.4^{\circ} \mathrm{C},-70.4^{\circ} \mathrm{C}$ and $-71.9^{\circ} \mathrm{C}$, respectively during vacuum cooling. It can be found that the temperature of vapour-condenser can be reduced continuously during vacuum cooling. Because the condensation ability of vapourcondenser is not smaller than the required one, the condenser can efficiently condense all the generated water vapour during the cooling. However, when the initial temperature of cold trap reached at $-71^{\circ} \mathrm{C}$, the temperature of cold trap had no variation during 


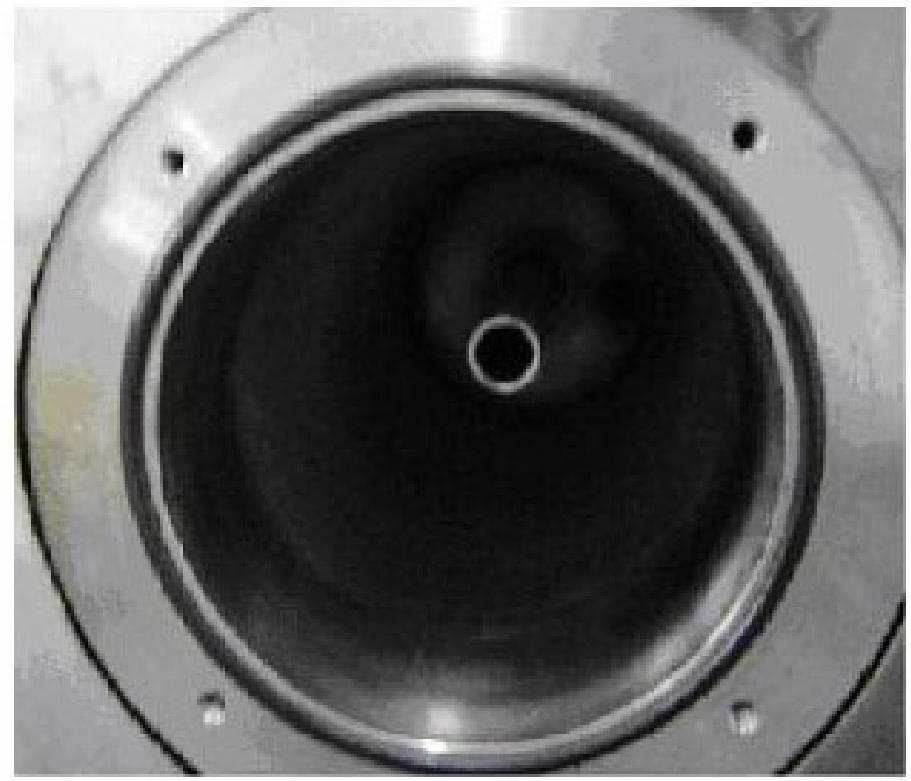

a. Cold trap before vacuum cooling of cooked meat

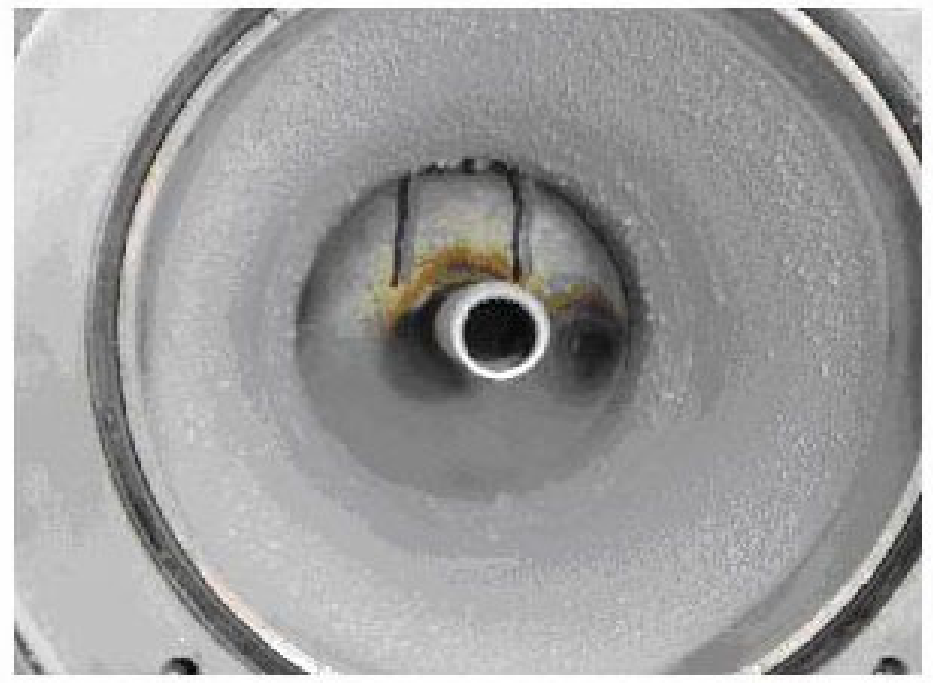

b. Cold trap after vacuum cooling of cooked meat

Fig. 5. Comparison the cold trap before vacuum cooling of cooked meat with after vacuum cooling of cooked meat 


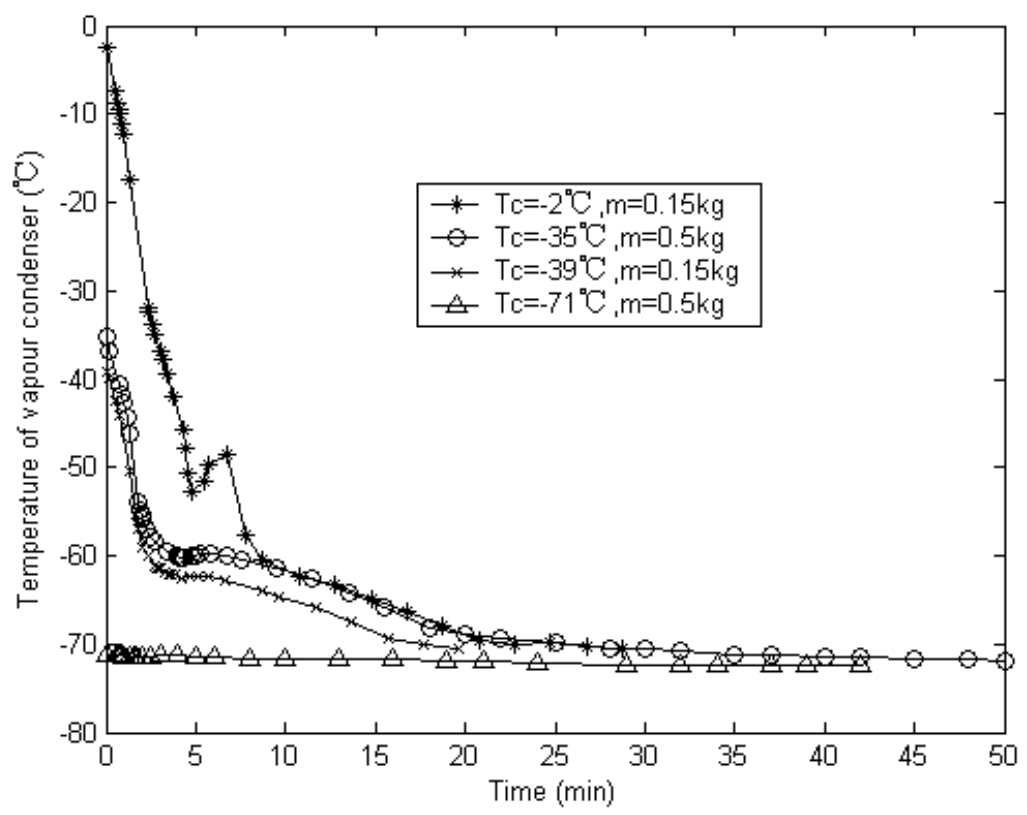

Fig. 6. The variation of temperature of vapour condenser in different experimental conditions

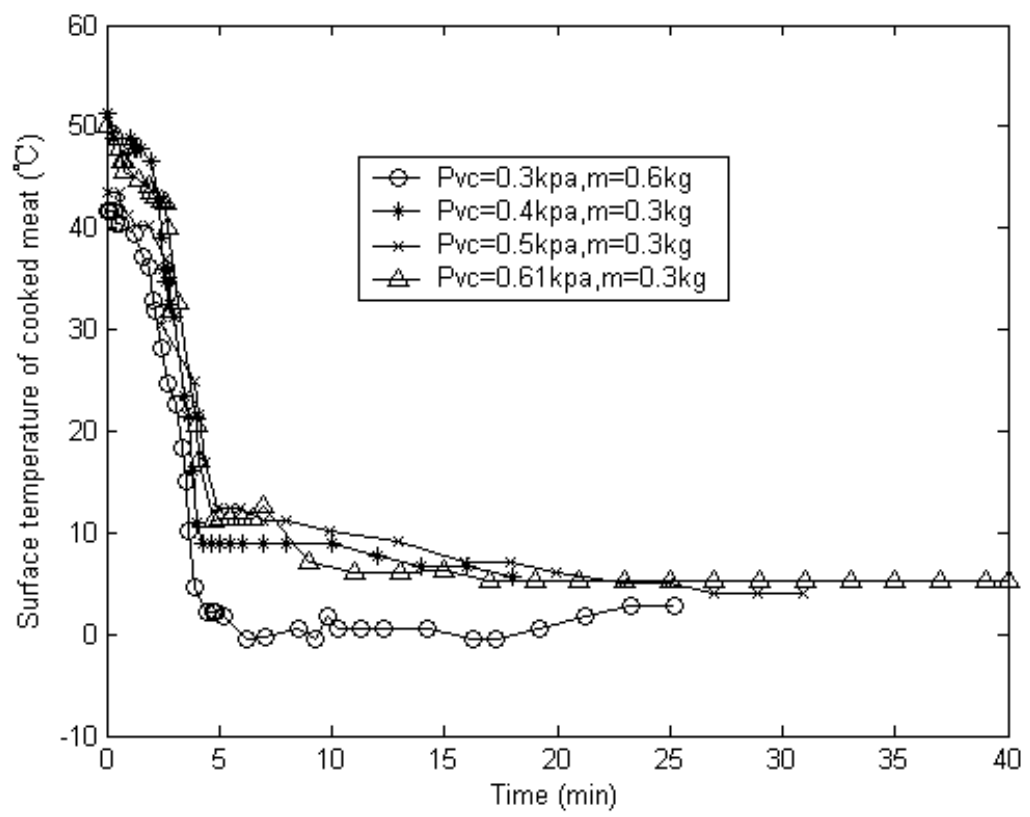

Fig. 7. Effect of the pressure in the vacuum chamber on the surface temperature of cooked meat during vacuum cooling 
vacuum cooling, which can be seen from Fig. 6 . At the same time, the temperature of cooked meat reduced only from $74^{\circ} \mathrm{C}$ to $26.1^{\circ} \mathrm{C}$ within $42 \mathrm{~min}$, which is because the frost and ice at the surface of cold trap result in a significant heat resistance.

\subsection{The Effect of the Pressure in the Vacuum Chamber on the Cooling Rate during Vacuum Cooling}

Fig. 7 gives the effect of the pressure in the vacuum chamber on the surface temperature of cooked meat during vacuum cooling. Four different final pressure, $0.3 \mathrm{kPa}$, $0.4 \mathrm{kPa}, 0.5 \mathrm{kPa}$ and $0.61 \mathrm{kPa}$, in the vacuum chamber were chosen during vacuum cooling. It can be seen from Fig. 7 that if the final vacuum pressure in the vacuum chamber is $0.61 \mathrm{kPa}$, the surface temperature of cooked meat can be reduced from 50 ${ }^{\circ} \mathrm{C}$ to $5.2^{\circ} \mathrm{C}$ within $40 \mathrm{~min}$. When the final vacuum pressure in the vacuum chamber was reduced from $0.61 \mathrm{kPa}$ to $0.5 \mathrm{kPa}$, the surface temperature of cooked meat can be reduced from $43.5^{\circ} \mathrm{C}$ to $4^{\circ} \mathrm{C}$ within $31 \mathrm{~min}$. The final vacuum pressure in the vacuum chamber was kept at $0.4 \mathrm{kPa}$, the surface temperature of cooked meat varied from $51.2^{\circ} \mathrm{C}$ to $5.6^{\circ} \mathrm{C}$ within $18 \mathrm{~min}$. In the same case, the mass of cooked meat is $0.3 \mathrm{~kg}$, the final vacuum pressure in the vacuum chamber varied from $0.4 \mathrm{kPa}$ to $0.61 \mathrm{kPa}$, the cooling time will increase from $18 \mathrm{~min}$ to $40 \mathrm{~min}$. If the mass of cooked meat increased from $0.3 \mathrm{~kg}$ to $0.6 \mathrm{~kg}$, the final vacuum pressure in the vacuum chamber is further reduced from $0.4 \mathrm{kPa}$ to $0.3 \mathrm{kPa}$, the surface temperature of cooked meat can be reduced from $41.6^{\circ} \mathrm{C}$ to $2.7^{\circ} \mathrm{C}$ within $25 \mathrm{~min}$. On the other hand, during vacuum cooling, it can be found when the final vacuum pressure in the vacuum chamber was $0.3 \mathrm{kPa}$, the minimum surface temperature of cooked meat was $-0.5^{\circ} \mathrm{C}$, which shows that water freezes on the surface of cooked meat and has a negative effect on the cooked meat. It is well known that the boiling point changes as a function of saturation pressure, for a boiling temperature of $0^{\circ} \mathrm{C}$, the saturation pressure will be $609 \mathrm{~Pa}$. However, the experimental results show that the surface temperature of cooked meat is above $0^{\circ} \mathrm{C}$, when the vacuum pressure in the vacuum chamber is between $0.4 \mathrm{kPa}$ and $0.6 \mathrm{kPa}$. If the vacuum pressure in the vacuum chamber is further reduced to $0.3 \mathrm{kPa}$, the surface temperature is below $0^{\circ} \mathrm{C}$. This means that the vacuum pressure in the vacuum chamber can be reduced to below $0.6 \mathrm{kPa}$. At the same time, it should be noted that the vacuum pressure in the vacuum chamber should be above $0.4 \mathrm{kPa}$.

\section{Conclusion}

The temperature of vapour-condenser below $0^{\circ} \mathrm{C}$ and the final pressure in the vacuum chamber below $0.61 \mathrm{kPa}$ during vacuum cooling were experimentally analysed. The temperature of vapour-condenser, $-2^{\circ} \mathrm{C},-35^{\circ} \mathrm{C},-39^{\circ} \mathrm{C}$ and $-71^{\circ} \mathrm{C}$, and the final pressure in the vacuum chamber, $0.3 \mathrm{kPa}, 0.4 \mathrm{kPa}, 0.5 \mathrm{kPa}$ and $0.61 \mathrm{kPa}$, were chosen during vacuum cooling. The experimental results showed that water vapour becomes the frost on the surface of vapour-condenser when the initial temperature of vapourcondenser is below $0^{\circ} \mathrm{C}$, which is helpful to trap water vapour for vapour-condenser. However, if the temperature of vapour-condenser is reduced continuously to $-71{ }^{\circ} \mathrm{C}$, 
the cooling rate will not increase. Therefore, the temperature of vapour-condenser should be set around $-30^{\circ} \mathrm{C} \sim-40^{\circ} \mathrm{C}$. At the same time, it can be also found that the cooling time for vacuum cooling can be reduced when the final pressure in the vacuum chamber varied from $0.4 \mathrm{kPa}$ to $0.61 \mathrm{kPa}$. In addition, the surface temperature of cooked meat was above $0^{\circ} \mathrm{C}$. However, the surface temperature of cooked meat occurred freezing when the final pressure in the vacuum chamber was $0.3 \mathrm{kPa}$. It can be suggested that the final pressure in the vacuum chamber can be set between $0.4 \mathrm{kPa}$ and $0.61 \mathrm{kPa}$. In a word, it is feasible that the temperature of vapour-condenser below $0^{\circ} \mathrm{C}$ and the final pressure in the vacuum chamber below $0.61 \mathrm{kPa}$. In order to reduce the cooling time, the temperature of vapour-condenser should be set around $-30^{\circ} \mathrm{C} \sim-$ $40^{\circ} \mathrm{C}$ and the final pressure in the vacuum chamber can be defined at from $0.4 \mathrm{kPa}$ to $0.61 \mathrm{kPa}$.

\section{Acknowledgements}

Funding for this research was provided by Henan Provincial Department of Education (P. R. China).

\section{References}

1. Briley, G.C.: Vacuum cooling of vegetables and flowers. ASHRAE Journal 46(4), 52-53 (2004)

2. McDonald, K., Sun, D.-W., Kenny, T.: The effect of injection level on the quality of a rapid vacuum cooled cooked beef product. Journal of Food Engineering 47, 139-147 (2001)

3. Burfoot, D., Self, K.P., Hudson, W.R., Wilkins, T.J., James, S.J.: Effect of cooking and cooling method on the processing times, mass losses and bacterial condition of large meat joints. International Journal of Food Science and Technology 25, 657-667 (1990)

4. Desmond, E.M., Kenny, T.A., Ward, P., Sun, D.-W.: Effect of rapid and conventional cooling methods on the quality of cooked ham joints. Meat Science 56, 271-277 (2000)

5. Sun, D.-W., Wang, L.J.: Heat transfer characteristics of cooked meats using different cooling methods. International Journal of Refrigeration 23, 508-516 (2000)

6. Wang, L., Sun, D.-W.: Modelling vacuum cooling process of cooked meat-part 1: analysis of vacuum cooling system. International Journal of Refrigeration 25, 854-861 (2002)

7. Wang, L., Sun, D.-W.: Modelling vacuum cooling process of cooked meat-part 2: mass and heat transfer of cooked meat under vacuum pressure. International Journal of Refrigeration 25, 862-871 (2002)

8. Sun, D.-W., Hu, Z.: CFD predicting the effects of various parameters on core temperature and weight loss profiles of cooked meat during vacuum cooling. Computers and Electronics in Agriculture 34, 111-127 (2002)

9. Sun, D.-W., Hu, Z.: CFD simulation of coupled heat and mass transfer through porous foods during vacuum cooling process. International Journal of Refrigeration 26, 19-27 (2003) 
10. Wang, L., Sun, D.-W.: Effect of operating conditions of a vacuum cooler on cooling performance for large cooked meat joints. Journal of Food Engineering 61, 231-234 (2004)

11. Na, B., Webb, R.L.: New model for frost growth rate. International Journal of Heat and Mass Transfer 47, 925-936 (2004)

12. Kondepudi, S.N., O'Neal, D.L.: Performance of finned tube heat exchangers under frosting conditions. International Journal of Refrigeration 16(3), 175-180 (1993)

13. Yonko, J.D., Sepsy, C.F.: An investigation of the thermal conductivity of frost while forming on a flat horizontal plate. ASHRAE Trans. 73(2), 111-117 (1967) 